University of Nebraska - Lincoln

DigitalCommons@University of Nebraska - Lincoln

\title{
Longevity of Rodenticide Bait Pellets in a Tropical Environment Following a Rat Eradication Program
}

Are R. Berentsen

William C. Pitt

John D. Eisemann

USDA/APHIS/WS National Wildlife Research Center, John.D.Eisemann@aphis.usda.gov

Richard M. Engeman

USDA-APHIS-Wildlife Services, s_r100@yahoo.com

Follow this and additional works at: https://digitalcommons.unl.edu/icwdm_usdanwrc

Part of the Life Sciences Commons

Berentsen, Are R.; Pitt, William C.; Eisemann, John D.; and Engeman, Richard M., "Longevity of Rodenticide Bait Pellets in a Tropical Environment Following a Rat Eradication Program" (2014). USDA National Wildlife Research Center - Staff Publications. 1426.

https://digitalcommons.unl.edu/icwdm_usdanwrc/1426

This Article is brought to you for free and open access by the U.S. Department of Agriculture: Animal and Plant Health Inspection Service at DigitalCommons@University of Nebraska - Lincoln. It has been accepted for inclusion in USDA National Wildlife Research Center - Staff Publications by an authorized administrator of DigitalCommons@University of Nebraska - Lincoln. 


\section{Longevity of rodenticide bait pellets in a tropical environment following a rat eradication program}

\section{Are R. Berentsen, William C. Pitt, John D. Eisemann \& Richard M. Engeman}

Environmental Science and Pollution Research

ISSN 0944-1344

Volume 21

Number 3

Environ Sci Pollut Res (2014)

21:2283-2288

DOI 10.1007/s11356-013-2148-1

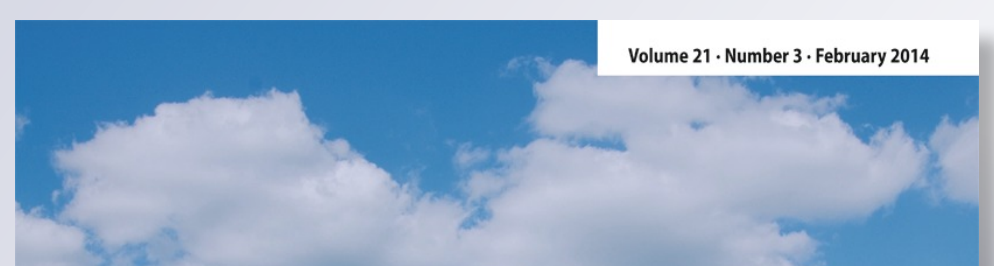

Environmental science and pollution Research

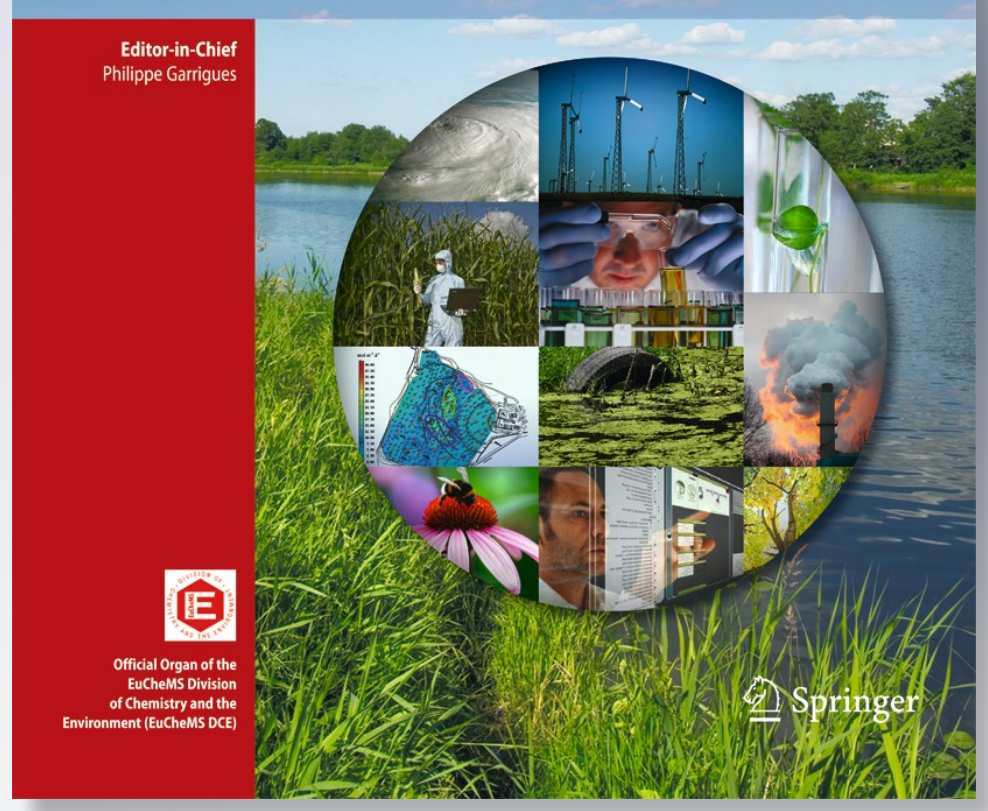

\section{黛 Springer}


Your article is protected by copyright and all rights are held exclusively by Springer-Verlag Berlin Heidelberg (outside the USA). This eoffprint is for personal use only and shall not be self-archived in electronic repositories. If you wish to self-archive your article, please use the accepted manuscript version for posting on your own website. You may further deposit the accepted manuscript version in any repository, provided it is only made publicly available 12 months after official publication or later and provided acknowledgement is given to the original source of publication and a link is inserted to the published article on Springer's website. The link must be accompanied by the following text: "The final publication is available at link.springer.com". 


\title{
Longevity of rodenticide bait pellets in a tropical environment following a rat eradication program
}

\author{
Are R. Berentsen • William C. Pitt • John D. Eisemann • \\ Richard M. Engeman
}

Received: 23 April 2013 / Accepted: 9 September 2013 / Published online: 21 September 2013

(C) Springer-Verlag Berlin Heidelberg (outside the USA) 2013

\begin{abstract}
Invasive rodents (primarily Rattus spp.) are responsible for loss of biodiversity in island ecosystems worldwide. Large-scale rodenticide applications are typically used to eradicate rats and restore ecological communities. In tropical ecosystems, environmental conditions rapidly degrade baits and competition for baits by non-target animals can result in eradication failure. Our objective was to evaluate persistence of rodenticide baits during a rat eradication program on Palmyra Atoll; a remote tropical atoll with intense competition for resources by land crabs. Following aerial application, bait condition was monitored in four terrestrial environments and in the canopy foliage of coconut palms. Ten circular PVC hoops were fixed in place in each of Palmyra's four primary terrestrial habitats and five rodenticide pellets were placed in each hoop. Five coconut palms were selected in three distinct regions of the atoll. One rodenticide pellet was placed on each of five palm fronds in each coconut palm. Fresh baits were placed in all monitoring locations after each broadcast bait application. Bait condition and survival was monitored for 7 days after the first bait application and 6 days after second application. Bait survival curves differed between applications at most monitoring sites, suggesting a decrease in overall rat activity as a result of rodenticide treatment. One terrestrial site showed near $100 \%$ bait survival after both applications, likely due to low localized rat and crab densities. Median days to pellet disappearance were one and two days for the first and second application, respectively. Differences in survival
\end{abstract}

Responsible editor: Philippe Garrigues

A. R. Berentsen $(\bowtie) \cdot$ J. D. Eisemann · R. M. Engeman National Wildlife Research Center, 4101 LaPorte Ave, Fort Collins, CO 80521-2154, USA

e-mail: Are.R.Berentsen@aphis.usda.gov

W. C. Pitt

National Wildlife Research Center-Hawai'i Field Station, PO Box 10880, Hilo, HI 96721, USA curves were not detected in canopy sites between bait applications. Median days to pellet disappearance in canopy sites were 2 and 4 days for the first and second application, respectively. Frequent rainfall likely contributed to rapid degradation of bait pellets in coconut palm fronds.

Keywords Environmental degradation · Invasive species . Land crabs $\cdot$ Rattus rattus $\cdot$ Rodent eradication $\cdot$ Rodenticide Tropical

\section{Introduction}

Invasive rodents, particularly rats (Rattus spp.), are a significant contributor to loss of biodiversity in island ecosystems, affecting over $80 \%$ of all islands or island chains worldwide (Atkinson 1985). Many islands lack predators and with little competition for resources and low risks of predation, introduced rat populations can flourish. Ecological damage inflicted by rats includes destruction of native flora and fauna, including threatened and endangered species (Towns et al. 2006). In some cases, eradication of invasive rodents has resulted in recovery of native populations or re-establishment of endangered species (Robertson et al. 1994).

Rodent eradication on islands often relies on the distribution of rodenticide bait to achieve the objective, which is to deliver a lethal dose of bait to every rodent on the island (Howald et al. 2007). A major concern in nearly every rodent eradication project is the protection of non-target species from exposure to the rodenticide. To reduce this risk, application rates are typically tailored to the unique characteristics of the island so that excessive quantities of bait are not applied. In addition, rodenticide baits are typically colored with a dye to decrease attractiveness to birds, further reducing non-target exposure risks (Brunner and Coman 1983; Moran 1999). Interspecific competition for bait between land crabs and rats 
can interfere with eradication efforts (Buckelew et al. 2005; Rodriguez et al. 2006). On tropical islands, land crabs can reach staggering numbers and densities of up to 1,400 crabs/ ha have been recorded (Cuthbert et al. 2012). They are known to forage heavily on rodenticide baits but appear not to be acutely impacted by the anticoagulant compounds in rodenticide baits (Pain et al. 2000).

Environmental conditions can affect rodenticide persistence and palatability, particularly in tropical environments. Studies in Hawai'i by Dunlevy et al. (2000) found that after 10 days, placebo RAMIK ${ }^{\circledR}$ Green baits were highly degraded and $74 \%$ had mold. On Palmyra Atoll, Howald et al. (2004) found CI-25 (brodifacoum 25-D) baits disintegrated within three days, but RAMIK ${ }^{\circledR}$ baits survived up to 5 days. Also on Palmyra Atoll, Alifano et al. (2010) demonstrated that placebo brodifacoum $25-\mathrm{W}$ baits degraded within two days in marine and intertidal environments (Alifano et al. 2010), but remained intact for up to seven days on some soil plots (Alifano and Wegmann 2011).

The persistence and palatability of baits are a major factor in the success of rodent eradication projects, but also significantly impact the risk to non-target organisms. Here, we describe the persistence of brodifacoum rodenticide baits following aerial application to a remote tropical atoll with intense competition from land crabs.

\section{Study Site}

Palmyra Atoll is located at approximately $6^{\circ} \mathrm{N}$ and $162^{\circ} \mathrm{W}$ in the Line Islands, $1,600 \mathrm{~km}$ south of Hawai'i. Palmyra is a National Wildlife Refuge, co-owned and managed by the US Fish and Wildlife Service and The Nature Conservancy. The atoll is comprised of approximately 50 islets in a horseshoe configuration around a central lagoon, surrounded by coral reef (Collen et al. 2009). The maximum elevation is $2 \mathrm{~m}$ and vegetation consists primarily of coconut (Cocos nucifera) palms, with stands of Pisonia grandis forest, patches of Scaevola sp. shrubs and meadows of Lepturas sp. The surrounding waters out to $80 \mathrm{~km}$ from shore are included within the Pacific Remote Islands Marine National Monument (The White House 2009). Average daytime temperature is $29{ }^{\circ} \mathrm{C}$ year-round, with an average annual rainfall of approximately $440 \mathrm{~cm}$. No native terrestrial mammals exist on the atoll and there is a rich diversity of crab species including land crabs (Cardisoma spp.), hermit crabs (Coenobita spp.), sand crabs (Ocypode spp.), and coconut crabs (Birgus latro). The atoll is also home to seasonal populations of migratory birds including red-footed boobies (Sula sula), bristle-thighed curlews (Numenius tahitiensis), and Pacific golden plovers (Pluvialis fulva). Palmyra Atoll was occupied by the US Navy during World War II and it is likely that the introduction of rats to the atoll occurred at this time.

\section{Methods}

Bait application

This study took place in June 2011concurrent with a rat eradication effort performed by the US Fish and Wildlife Service and a private contractor (Island Conservation, Santa Cruz, CA). Two aerial broadcast applications of a grain-based rodenticide pellet (brodifacoum 25-W: Conservation, EPA Reg. No. 56228-36, Supplemental Label-Palmyra Atoll) were performed. A more complete description of the rat eradication effort and bait application methods can be found in Engeman et al. (2013). Our objective was to determine the survival rate of rodenticide bait in terrestrial and arboreal environments following aerial rodenticide bait application. We expected that as a result of depressed rat populations after the first application bait survival times would increase from the first application to the second.

\section{Terrestrial monitoring}

Ten circular PVC plastic hoops (Hula Hoops) with and external diameter of $90.5 \mathrm{~cm}$ were fixed in place 3-5 m apart within representative patches of each of Palmyra's four primary terrestrial habitat types: coconut palm forest, Scaevola shrubland, Pisonia forest, and Lepturas meadow (Fig. 1). Each hoop was visually divided into four quadrants and a single bait pellet was placed within each quadrant with one pellet in the center (five pellets per hoop). Baits were monitored daily for 7 days after the first application and six days after the second application. Bait condition was classified as follows:

1. Present/ palatable: bait condition ranging from hard, intact and whole to soft, intact and partially gone.

2. Present/unpalatable: baits that had begun to disintegrate into granules due to environmental exposure.

3. Not present: bait completely removed.

\section{Arboreal monitoring}

We randomly selected five coconut palms approximately 4 $5 \mathrm{~m}$ in height in each of three areas: West Camp, North Beach and Aviation (Fig. 2). In each tree, we labeled five palm fronds with the tree number, frond, and bait numbers. We placed a single bait pellet on each labeled frond, with added leaves between the frond and the trunk to avoid losing the bait pellet. Individual baits were monitored for presence and condition as described for the terrestrial monitoring.

Data analysis

We examined bait survival using nonparametric product-limit survival analysis (Kaplan and Meier 1958) and we applied 

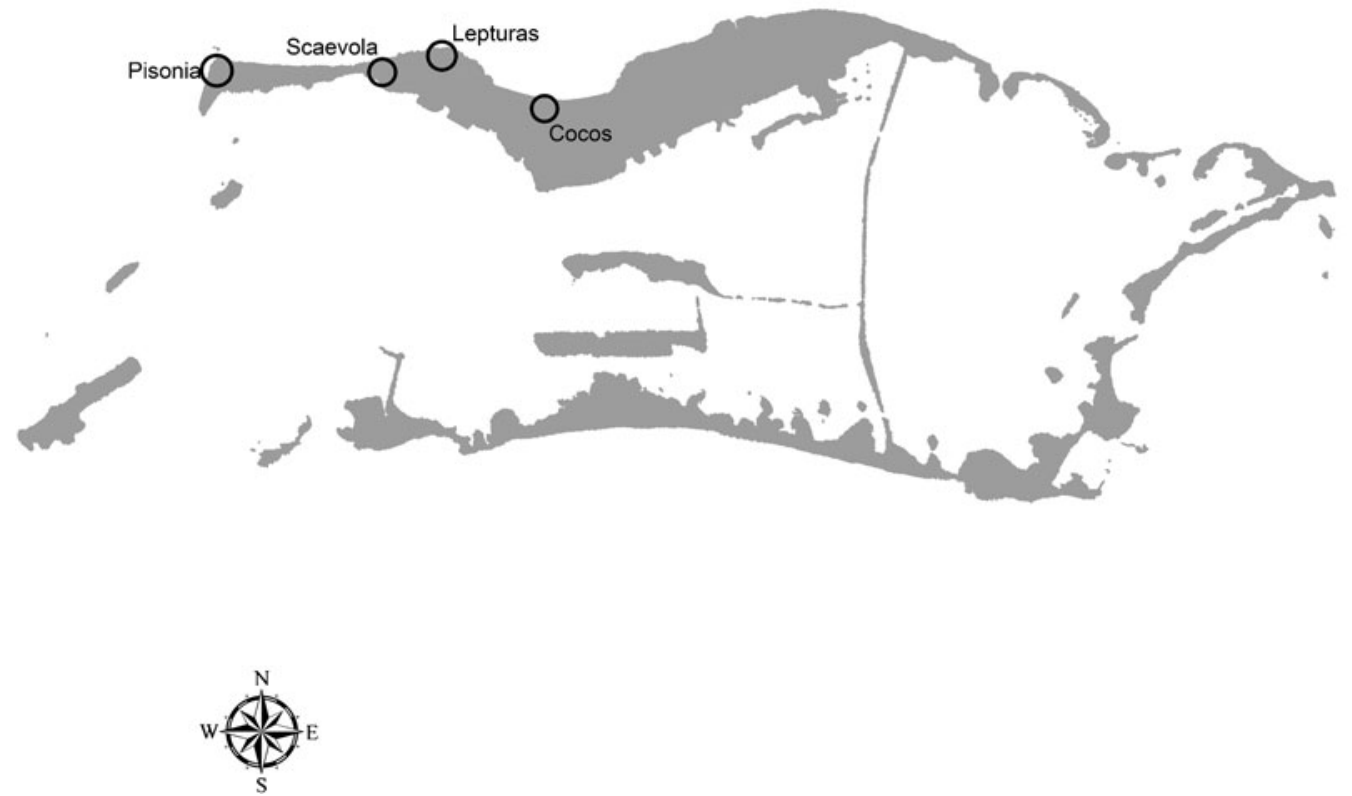

Fig. 1 A map of the four sampling locations used to measure terrestrial bait fate during the Palmyra Atoll rat eradication, 2011
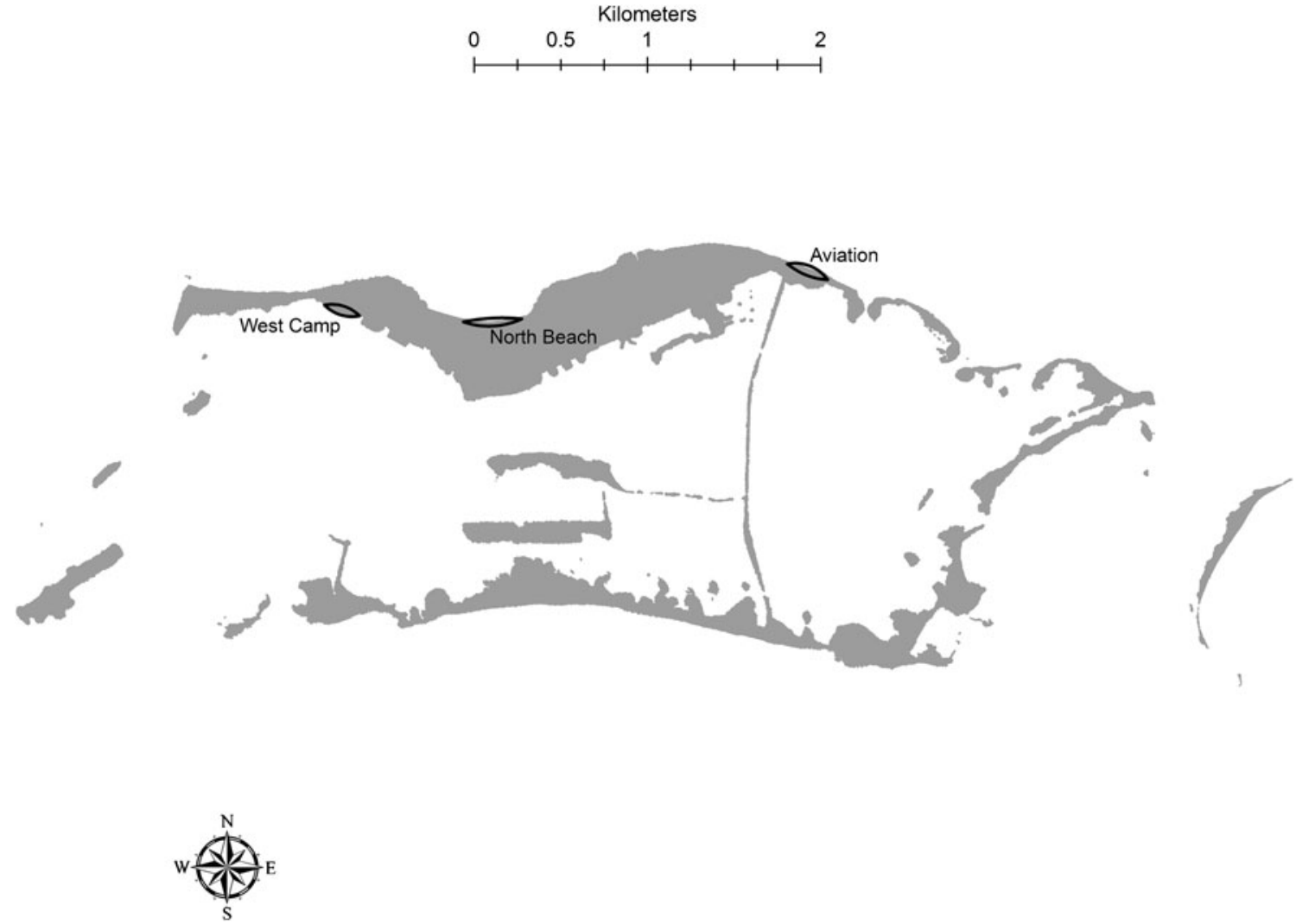

Fig. 2 A map of the three sampling locations used to measure canopy bait fate during the Palmyra Atoll rat eradication, 2011 
Wilcoxon comparisons to survival curves (Kalbfleish and Prentice 1980) between the two applications for each area. Similarly, we compared bait survival curves among different habitat types. Because the population reduction of rats through the two bait applications would be expected to influence the relative differences in population numbers among habitats (i.e., populations in all habitats trending towards zero after initial bait application), we compared bait survival among areas separately for each application. For all survival analyses, we defined a "censoring point" as the observation day on which bait became unavailable for monitoring (withdrawn from the study) either by (1) becoming unpalatable or (2) remaining palatable but still available on the last day of the observation period. Censoring allows the use of survival times from all observations until baits were removed or until the censoring event. Analyses were carried out using PROC LIFETEST in SAS (SAS Institute 2004).

Although bait placement in the palm canopies in different areas could be considered the same general habitat, the terrestrial rat populations within those areas may have been different and influenced the numbers of rats in the canopies and, hence, the rates at which baits were taken. Therefore, analyses were conducted as for the terrestrial monitoring where bait survival was compared between the applications within each area separately, and the areas were compared to each other separately for the two bait applications.

\section{Results}

\section{Terrestrial bait fate sampling}

The bait survival curves for the two aerial applications at the Scaevola site differed (Wilcoxon $\chi^{2}=8.971, d f=1, p=0.0027$ ). The median bait survival time (time to disappearance) for the first application was 1 day, and increased to 3.5 days for the second application, suggesting a reduction in the rat population. A similar scenario occurred at the Pisonia site where the survival curves again differed (Wilcoxon $\chi^{2}=15.1971, d f=1$, $p=0.0001)$. Here, the median survival time increased from 1 day to 3 days. In contrast, differences between bait survival curves could not be detected for the Cocos site (Wilcoxon $\chi^{2}=00.062, d f=1, p=0.80$ ). The median bait survival time for the two applications was 5 days in each case, higher than any of the survival times from the other two areas analyzed. Only 7 of 100 baits from the Lepturas site were removed between both applications and, the remaining baits remained palatable until the end of each observation period making it impossible to calculate median survival times or to find a difference between survival curves (Wilcoxon $\chi^{2}=0.0001, d f=1, p>0.99$ ). Given the high level of bait persistence across both applications, the Lepturas site was excluded from further analyses to avoid skewing results.

There were differences in survival curves from the three analyzed areas for the first bait application (Wilcoxon $\left.\chi^{2}=63.351, d f=2, p<0.0001\right)$. Even though the median bait survival times substantially increased for both the Scaevola and Pisonia sites during the second application, neither approached the median survival time of 5 days at the Cocos site, again resulting in considerable differences among the survival curves for the second application (Wilcoxon $\chi^{2}=12.264, d f=2$, $p=0.0022$ ).

Arboreal bait fate sampling

Assessing survival for the canopy baits was more difficult due to the high number of censored observations (Table 1). For the West Camp area, $>50 \%$ of the baits survived until the end of the observation period after each application, true medians could not be calculated, and differences in survival curves were not detected (Wilcoxon $\chi^{2}=1.529, d f=1, p=0.22$ ).

Too many of the observations were censored for both the Aviation and North Beach areas for both drops for median survival to be calculated and differences in survival curves were not detected (Wilcoxon $\chi^{2}<2.62, d f=1, p>0.11$, in both cases). Similarly, differences were not detected among survival curves for the three areas during either of the two applications (Wilcoxon $\chi^{2}<2.32, d f=2, p>0.31$, in both cases).

Bait palatability

Baits on the ground were highly likely to remain palatable, with only 12 and $2 \%$ of all baits becoming unpalatable after the first and second applications, respectively (Table 1). Median time to unpalatability was 6 days for each application. A completely contrary situation occurred for the baits in the canopy. Of the uneaten baits $100 \%$ and $86.8 \%$ became unpalatable after the first and second applications, respectively (Table 1). Median time to unpalatability was 7 days for the first application and 5 days for the second.

\section{Discussion}

Baits must remain attractive to the target species for an eradication effort to be effective. Unpalatable bait has essentially the same effect as having no bait. This was a particular concern on Palmyra Atoll where bait experienced frequent heavy rains and high humidity, which could potentially cause rapid bait disintegration. Total rainfall was 15.2 and $60.6 \mathrm{~mm}$ during the first and second monitoring periods, respectively (The Nature Conservancy, 2011, unpublished data). On our terrestrial study plots, relatively few baits lingered long enough to become unpalatable, which we attribute to the ability of rainwater to percolate through the porous soil surface thereby allowing baits to dry and remain intact. A much higher proportion of baits became unpalatable in the canopy 
Table 1 Proportion of censored baits divided by category and median days to unpalatable condition for rodenticide baits on Palmyra Atoll, 2011

\begin{tabular}{|c|c|c|c|c|c|c|c|}
\hline \multirow[t]{2}{*}{ Site } & & \multicolumn{3}{|l|}{ Application 1} & \multicolumn{3}{|l|}{ Application 2} \\
\hline & & $\begin{array}{l}\text { Proportion palatable/ } \\
\text { not taken }\end{array}$ & $\begin{array}{l}\text { Proportion } \\
\text { unpalatable }\end{array}$ & $\begin{array}{l}\text { Median days to } \\
\text { condition }\end{array}$ & $\begin{array}{l}\text { Proportion palatable/ } \\
\text { not taken }\end{array}$ & $\begin{array}{l}\text { Proportion } \\
\text { unpalatable }\end{array}$ & $\begin{array}{l}\text { Median days to } \\
\text { condition }\end{array}$ \\
\hline \multirow[t]{4}{*}{ Terrestrial } & Scaevola & 0 & 0 & N/A & $11(22 \%)$ & 0 & N/A \\
\hline & Cocos & $4(8 \%)$ & $6(12 \%)$ & 6 & $19(38 \%)$ & $1(2 \%)$ & 6 \\
\hline & Pisonia & 0 & 0 & N/A & 0 & 0 & N/A \\
\hline & Lepturas $^{\mathrm{a}}$ & $46(92 \%)$ & 0 & N/A & $47(94 \%)$ & 0 & N/A \\
\hline \multirow[t]{3}{*}{ Canopy } & West Camp & 0 & $13(52 \%)$ & 7 & $1(4 \%)$ & $14(56 \%)$ & 5 \\
\hline & Aviation & 0 & $15(60 \%)$ & 5 & $4(16 \%)$ & $15(60 \%)$ & 5 \\
\hline & North Beach & 0 & $17(68 \%)$ & 7 & $2(8 \%)$ & $17(68 \%)$ & 5 \\
\hline
\end{tabular}

${ }^{a}$ Data included in this table for clarity, but not included in statistical comparisons because of the unique results observed in this habitat

where rainwater can collect in palm fronds and soak some baits, causing them to disintegrate more rapidly.

Another factor affecting longevity of baits can be competition by non-target species. On Palmyra Atoll, the only significant competitor for baits was land crabs. To compensate for high competition by land crabs, application rates were increased to satiate crabs while leaving enough bait available to rats. Median bait survival time increased between treatments for the Pisonia and Scaevola sites. Our data indicate an increase in the number of censored baits for Scaevola site after the second application, but at Pisonia no baits were censored after either application; all baits were removed. This phenomenon could be a function of differing densities of land crab species (i.e., hermit crabs vs. Cardisoma spp.) between the two habitats. Wegmann (2008) suggested that hermit crabs are the most common land crab to interfere with baiting operations through gregarious feeding, particularly in areas of uneven bait broadcast. The foraging behavior of Cardisoma spp. is quite different. When encountering a food source, Cardisoma spp. typically either eat immediately or remove food to their burrows (Burrgren and McMahon 1988). Howald et al. (2004) reported Cardisoma spp. densities in Pisonia habitat were approximately $50 \%$ higher than in Scaevola habitat, with the opposite distribution for hermit crabs. The tendency of Cardisoma spp. to cache food sources in burrows combined with the higher local population density may help explain why bait was removed more quickly at the Pisonia site. The median survival time of bait at the Cocos site was the same (5 days) after each bait application, although the proportion of censored baits doubled between applications. Assuming a similar rate of bait consumption by crabs between bait applications, it is probable that the overall increase in bait survival on terrestrial plots between applications was the result of reduced bait consumption by rats.

The high bait survival at the Lepturas site was unexpected. However, the Lepturas site is open habitat with little to no vegetative cover. As a result, there may have been very little rat activity as rats typically prefer habitats with vegetative cover (Cox et al. 2000). In addition, Howald et al. (2004) report open habitat types have the lowest crab densities on the atoll. Low localized densities for both species likely contributed to near $100 \%$ bait survival for this site. A high rate of rodenticide bait survival in open habitats may have implications for availability to non-target species in future eradication efforts and influence decisions on whether or not certain habitats should be baited. This site had also received a prior broad spectrum herbicide treatment which may have contributed to an unfavorable habitat for both rats and crabs.

The high proportion of censored observations at the canopy sites was due to pooled rainfall in palm fronds degrading baits and low rat activity in the canopy. Space use by rats on Palmyra is not distributed evenly between the canopy and the ground. Research by Howald et al. (2004) found that rats captured in the canopy spent over $50 \%$ of their time on the ground whereas rats captured on the ground spent only $29 \%$ of their time in the canopy. Thus, rats spend most of their time on the ground, which is supported by our observation that less than $50 \%$ of baits in the canopy were removed. The uneven spatial distribution of rats has implications for the number of canopy baits accessed by rats and whether direct canopy baiting is necessary to achieve the objective of making bait available to all rats on the island.

Overall bait survival increased after the second bait application, suggesting a decreased consumption by rats and a relatively constant rate of consumption by crabs. This difference suggests that bait persisted long enough to be effectively consumed by rats while overcoming competition by land crabs.

Results from this study have implications for rat eradication efforts on other tropical islands. If aerial broadcast baiting is to be used, it must be conducted in such a manner to ensure adequate bait distribution and persistence in areas with high rodent abundance, while not applying excessive bait to marginal habitat. A thorough understanding of the land crab population or other competitors for bait on an island considered a candidate for rat 
eradication can help in establishing application rates to overcome competition and increase chances of success. In addition, bait degradation due to heavy and frequent rains can have a profound impact on bait longevity and availability to rats, particularly when baits are located in an overstory canopy. It is critical that baits persist and remain attractive to rats. Furthermore, an understanding of local rat ecology can assist in determining whether direct bait application in canopies is warranted, given the potentially high rate of bait disintegration due to pooled rainwater and rodent foraging on the ground.

Acknowledgments The authors wish to thank T. McAuliffe, K. Hayes, A. Meyer, and S. Hathaway for field assistance.

\section{References}

Alifano A, Wegmann A (2011) The ecotoxicology and palatability of two rodenticide products: field-based assessment at Palmyra Atoll. Unpublished report to the Palmyra Atoll Rainforest Restoration Project. 49 pp

Alifano A, Wegmann A, Pott M, Oberg E (2010) Palmyra Atoll restoration project: rat genetic sampling, detection method testing, and canopy bait testing. Unpublished report. $26 \mathrm{pp}$

Atkinson IAE (1985) The spread of commensal species of Rattus to oceanic islands and their effects on island avifaunas. In: Moors PJ (ed) Conservation of island birds. ICBP Technical Publication No. 3, Cambridge, pp 35-38

Brunner H, Coman BJ (1983) The ingestion of artificially coloured grain by birds and its relevance to vertebrate pest control. Aust Wildl Res 10:303-310

Buckelew S, Howald GR, Wegmann A, Sheppard J, Curl J, McClelland P, Tershy B, Swift K, Campbell E, Flint B (2005) Progress in Palmyra Atoll Restoration: rat eradication trial 2005. Island Conservation Report, $46 \mathrm{pp}$

Burggren WW, McMahon BR (1988) Biology of the land crabs. Cambridge University Press, Cambridge

Collen JD, Garton DW, Gardner JPA (2009) Shoreline changes and sediment redistribution at Palmyra Atoll (Equatorial Pacific Ocean) - 1874-present. J Coastal Res 25:711-722

Cox MPG, Dickman CR, Cox WR (2000) Use of habitat by the black rat (Rattus rattus) at North Head, New South Wales: an observational and experimental study. Austral Ecol 25:375-385
Cuthbert RJ, de Brooke ML, Torr N (2012) Overcoming hermit-crab interference during rodent-baiting operations: a case study from Henderson Island, South Pacific. Wild Res 39:70-77

Dunlevy PA, Campbell EW, Lindsey GW (2000) Broadcast application of a placebo rodenticide bait in a native Hawaiian forest. Int J Biodet Biodeg 45:199-208

Engeman RM, Pitt WC, Berentsen AR, Eisemann JD (2013) Assessing spatial variation and overall density of aerially broadcast toxic bait during a rat eradication on Palmyra Atoll. Environ Sci Pollut R 20: 480-487

Howald G, Donlan CJ, Galvan JP, Russell JC, Parkes J, Samaniego A, Wang Y, Veitch D, Genovest P, Pascal M, Sanuders A, Tershy B (2007) Invasive rodent eradication on islands. Conserv Biol 21: $1258-1268$

Howald G, Samaniego A, Buckelew S, McClelland P, Keitt B, Wegmann A, Pitt WC, Vice DS, Campbell E, Swift K, Barclay S (2004) Palmyra Atoll Rat Eradication Assessment, August 2004: trip report. Technical report to US Fish and Wildlife Service, Honolulu, HI, 61pp

Kalbfleish JD, Prentice RL (1980) The statistical analysis of failure time data. Wiley, New York

Kaplan EL, Meier P (1958) Nonparametric estimation from incomplete observations. J Am Stat Assoc 53:457-481

Moran BJ (1999) Rejection of dyed field rodent baits by feral pigeons and chukar partridges. Phytoparasitica 27:9-17

Pain DJ, de Brooke ML, Finnie JK, Jackson A (2000) Effects of brodifacoum on the land crab of Ascension Island. J Wildlife Manage 64:380-387

Robertson HA, Hay JR, Saul EK, McCormack GV (1994) Recovery of the Kakerori: an endangered forest bird of the Cook Islands. Conserv Biol 8:1078-1086

Rodriguez C, Torres R, Drummond H (2006) Eradicating introduced mammals from a forested tropical island. Biol Conserv 130:98-105

SAS Institute (2004) SAS/STAT User's Guide, Volume 3. SAS Institute, Carey, NC

House TW (2009) Establishment of Pacific Remote Islands Marine National Monument: a proclamation by the President of the United States of America, January 6, 2009. Office of the Press Secretary. White House News, Washington DC

Towns DR, Atkinson IAE, Daugherty CH (2006) Have the harmful effects of introduced rats on islands been exaggerated? Biol Invasions 8:863-891

Wegmann A (2008) Land crab interference with eradication projects: phase I-compendium of available information. Pacific Invasives Initiative. The University of Auckland, New Zealand, $30 \mathrm{pp}$ 